\title{
sciendo
}

DOI: $10.2478 /$ rjp-2019-0019

Rom J Psychoanal 2019, 12(2):109-118

Rom J Psychoanal

\section{MOURNING, SEPARATION, MENTAL SPACE}

Anatol Nacu ${ }^{8}$

\begin{abstract}
The work of mourning and organization of the mental space may be seriously disturbed by the real loss of the object and the way how communication with the "still alive" objects is built. Certain obstacles in communication with significant people make the mental separation difficult. The problem of separation, individuation and building of somebody's own mental space is linked to the way in which the child mourns in relation to the central objects of early childhood. Especially the real loss of a parental object during the early childhood implies a traumatic moment which will excessively dramatize the oedipal issues. In this context, the analysis of the infantile material and development of an analytical work, which would perlaborate the trauma of the loss under a full oedipal conflict of one of the parents, as well as the subjectivation difficulties deriving from this trauma are the indispensable elements of a psychoanalytic work.
\end{abstract}

Key words: mourning, separation, objectalising function, construction, perlaboration, subjectivation.

\section{Introduction}

The difficult psychoanalytic cases frequently start with a therapy of a patient with neurotic functioning, and during a certain moment of the cure important narcissist and preoedipal problems occur. The difficulties of these problems, including the object relations are outlined in the transference - counter-transference relation and may be gradually solved by

\footnotetext{
${ }^{8}$ Romanian Society of Psychoanalysis; anatolnacu@yahoo.com
} 
returning to the neurotic functioning by the end of the analytical cure. The submitted clinical material will serve as basis for describing the difficulties related to the therapeutic work with a patient subject to mourning during the oedipal period, with severely disturbed process of evoking, constructing and creating the image of the deceased father because of the patient's mother attitude. In Constructions in Analysis Freud states that the analyst should guess or preferably, to construct what was forgotten (S. Freud, 1937, p. 327).

In case of mourning as E. Sechaud (2005) writes, the pressure of reality makes the subject reject the object, and this represents a difficult and painful process with double renunciation, abandon what has happened and what did not happen; what the subject received and what the subject did not receive (E. Sechaud, 2005, p. 36). The symbolising processes in this respect become indispensable for working with the mourning.

Mourning organises what Green calls the "objectalising function", which may lead to interiorisation of something which does not have the features of the real object and this phenomenon has symbolisation as a major consequence (apud E. Sechaud, 2005, p. 37).

Defusion of instincts is maintained in the interest of death instinct, organizing the deobjectalising function, which attacks all the investments and aims to achieve withdrawal. In correlation with sublimation, it is a process of de-sublimation, that is meant to lead to its degradation. The resources of splitting may emerge between these two options in such a way that a part of Ego will succeed into sublimation, while the second will remain in pain, cruel representations, hate, persecution or internal vacuum. In this case, the life instinct, and the death instinct, remain separated. This is the result of missed or unfinished mourning, hoping the analysis could give them an impulse (J. Cournut, 1983, apud E. Sechaud, 2005, p. 37).

\section{Clinical material}

The patient described in this text, appealed for therapy, at the age of fifty, complaining about having problems in relation with his boss. The patient is obsessed and pressed by the idea that his boss might be dissatisfied with his activity. From the very start, the patient creates a link with the death of his father (at the patient's age of five), the respective event being responsible for what is happening to him, but he does not see where this idea could have come from. The cure represents a classical psychoanalytical approach, which continues for seven

years. Three stages may be relatively clearly delimited within it. During the first stage we have worked mainly with the mourning of a part of his father's split image, when a number of 
memories were updated about the "real" ("good") father, and the image of an oedipal father was more or less absent during this period. In the development of the "real" ("good") father mourning, the father's image was rather faint, gradually gained some consistency, but still in a very poor and opaque version. Nevertheless, based on these memories, the patient formulated a conclusion during one of the meetings that his father loved him more than his mother. Initially the analytical labour was rather ambivalent: sometimes rather easy, associative, unrealphantasmagorical; other times, rather difficult because of the cumbersome and hostile atmosphere, spiced up with reproaches and requests for help. The positive transfer was present almost constantly, just like the negative transfer, almost constant, but less obvious. The negative transfer is felt by the analyst in the meetings' ambience in the patient's reproaches regarding the lack of dynamism (it seems that the patient did not notice or was cancelling positive movements, which were actually noted by the analyst and, periodically, even by the patient) and in the comparisons made by the patient between what was happening during sessions and what some psychoanalyst authors, like Freud or Greenson, were writing. For a period of time, the patient's request was related to the idea of having the possibility to bring his father back to life, because the patient's condition could not be changed because the father was missing. At the same time, the patient acknowledged that this was impossible. E. Sechaud (2005) writes that reality in mourning has the function of interpreting, imposing a new vision, without immediate modification of what feeds the illusion of the object's persistence. Time is needed for the present reality of the lost object to switch to the finished past (E. Sechaud, 2005, p. 43).

The image of a child educated in the spirit of the ideal emerges in the cure from the very beginning. The lack of information about the father, provided by the patient's mother, limited itself to an iconic image of a gentle and polite father, who never has raised his voice in conversation with the mother and loved her deeply. In patient's opinion, his mother raised him in idealization spirit so as to prepare the patient to meet her daily needs as well as an inherited debt from his father. Another legacy was the idea that his mother willing to "rescue" the patient from the father's aggressive attitude, and has said the father "to die under wheels", that actually has happened. The patient became an involuntary accomplice of his mother's thought, although he did not have clear memories of his father's violent attitude.

The second stage of the therapy involves negative transfer prevailing as a result of updating the image of the oedipal father, projected on the analyst. This stage starts with some events related to the high creativity period of the patient followed by a series of events linked with the patient's boss and his dissatisfactions, during this time the patient accused the therapy 
of being inefficient, where he criticized the analyst and accused him of being unprofessional and not qualified enough. The free associations and floating attention were the main working methods used during these two stages. After the second period, which was rather difficult for patient and analyst, during which became possible to access the emotional feelings that were inhibited until that moment, finally it was possible to pass to another level of work.

The stage of working on the image of the oedipal ("bad") father followed in the context of a rather good therapeutic alliance, during which what was happening to the patient in transference is an object of work and not a motive for a direct attack on analyst or people around. The patient was talking about the absence of a communication experience, which could have been learned in relation with father, and about the mother's influence on his relations with men, which emerged from problems that in the beginning seemed to be of oedipal origin. These problems became central in the last stage of working with the patient. During the last stage, the patient's free associativity was not sufficient anymore for the cure, and the constructions inside therapy became more present. The patient backs up the idea that the source of his problems may be found only in what happened before the death of this father (the pre-oedipal period), having very concise memories about this period, which were coming back to him rather slowly in therapy. The patient always felt himself as a continuation of his mother's expectations, in his professional and family achievements. When meeting with her friends the mother would mention that she did not love the father, and the patient witnessed this. The patient was placed by his mother in the position of "little man", sometimes with important accents put on education which often been a pretext for conflicts between the parents, with the mother "defending" the boy. At the same time, the mother denied the child's wishes and needs, so that, during his entire life, the patient was thinking first of all about his mother's reaction in all the decisions that he made. And during the cure, one of his ideas was related to the wish to cure the mother, but it was not so clear for him what exactly to cure. The passive sadness gradually disappeared from the patient's way to be. C. Chabert (1999, p. 1445) suggests the image of the child subject to seduction, foolishness, crime and sacrifice as an extreme image of the child's death in the sense of a borderline-representation of melancholia.

The patient was always evoking mnemonic problems, like impossibility to remind himself during the days spent at the seaside one the eve of his father's death, although his mother was saying that the father was around and is playing with the patient. Important discussions from previous meetings were forgotten, the patient was asking to be reminded what we discussed, and after the meeting he would spend some time in the lobby to write down 
moments from the meeting. Freud says that forgetting some impressions, scenes or experiences is mainly reduced to "removing" them. When the patient talks about "forgotten" things, very seldom he forgets to add: "I always knew about this, but I just did not think about it" (S. Freud, 1914, p. 140).

The relations with men were also influenced by the unfinished mourning regarding the incestuous/oedipal objects, marked by unconscious homosexuality, competition with men - a competition in which he felt he was underperforming, showing passiveness, with him anxiously awaiting the "call from the boss". During the negative transfer period, the patient increasingly often acknowledged how poor the image of his father was, invoking relatively few positive images. The majority of concise memories, partially suggested by his mother, mainly with a negative connotation: the father would shout at him when he dropped a spoon. The father was disappointed when the child makes a slip of the tongue, saying "motofilm" instead of "multfilm", which in Russian means cartoon. He talked about his father in terms of huge fear he was shaking in his presence, as the mother described. T. Bokanowski (2019) talks about the incestuous link with the father, the need to suppress the representation of feminine position towards his father ("If father beats me, it means he loves me"), which is an active and central phantasm. This stage of the phantasm clarified the position of the child towards paternal violence, which is admired, envied and feared and the child tries to show it closer in a regressive manner (T. Bokanowski (2019, p. 60). In the phantasm "a child is beaten", we can see the avatar and the framing of the original phantasm of child's seduction by the adult, among others, including by the mother. The boy interposes his father as a third person so as to clear himself from the primary seduction of his mother, who is the source of terror related to phantasms of fusion, ingestion, annihilation (T. Bokanowski, 2019, p. 60-61). The image of the father transferred by the patient's mother cannot reach the consistency of a third person.

The patient could not imagine that those men who had a positive, supportive, protecting attitude in relation with him, could contribute to the image of his father through some of their features. Moreover, the patient's relation with his daughter, based on a feeling of fatherdaughter love, could not serve as model for identification with his father. The same net separation is also seen in his mother's image, who cannot be perceived as somebody who play both roles: a loving mother and a castrating one mother. Some aspects were felt during the therapy sessions, which are difficult to be represented in the form in which they were kept; the constructions which were delivered or co-created together with the analyst allowed the development, clarification and elicitation of a number of aspects of the pre-oedipal and oedipal 
periods (the father at the seaside with the patient on the eve of his death, the father who returned from the army, the mother who could be sensitive to something emotional, mother who could accept and love the child unconditionally etc.).

When he was able to express his hate towards his father, after the constructions worked with the patient, he got the possibility to feel other "live" and positive memories about his father: the father who tries to protect him in his mother's belly by taking over a number of difficult tasks from her, the resourceful father who managed could do special things. This feeling of hate allowed for the idea of separation from the mother's representative apparatus to emerge: "to feel the hate, it is necessary to have somebody separate from me", says the patient during one of the meetings. The vagueness of father's image as object of mother's love is linked to the vagueness of his own position in life, the difficulty of identifying himself as a child of this man, in the context of oedipal conflictuality.

In Chasseguet-Smirgel's opinion (1990), the child helped by his mother or by specific circumstances of his personal history, projects the Ideal of his Ego on pre-genital movements and upon partial objects, instead of projecting them on the father with the aim to identify himself with him. In this respect, the child should not grow up, because his mother likes him the way he is, and he does not even have to take the father's place, because he has already taken it. To preserve this illusion of taking his father's place, the child has to perceive his small pre-genital penis as a genital penis and he does this through idealization (J. Chasseguet-Smirgel, 1990, p. 93).

Another important moment is related to the feeling of guilt and anxiety. The patient says that if accusations come from the outside world, they are immediately found within him the most appropriate place to locate, as if he could not exist without these accusations. In this respect Freud says: "...through the moral masochism, the moral is again sexualised, the Oedipus complex - is revived and paves the way for a regression from the moral to the Oedipus complex. ... To provoke the punishment through this last parental representative, the masochist should do something inappropriate, work against his own advantage, destroy the perspectives opening to him in the world ...” (S. Freud, 1924, p. 273).

The contrast between the patient's conscious speech, in which he would place himself on clear positions, constructing a clear oedipal structure with well-determined roles in the relation with the mother and the father and the consequence of the part of the mourning regarding the "real" father and his oneiric life, where things were frequently coming back to 
the pre-oedipal period, when he continues to be a kind of mother's partner and a successful competitor in his relation with the father. He was talking about the impossibility to overcome this position, although he noticed the positive movements.

The patient's suffering pain is really special due to its tenacity. Green quotes Freud, who states that suffering in moral masochism does not originate from loved object, but from anyone. This remark seems to support the idea of narcissistic pain, when the person is mainly concerned with the condition she/he is looking for rather than being attached to an object (A. Green, 1993, p. 147). This thing has been noted a number of times by the analyst and the patient, in relation to the communication with different persons of the patient, as well as with the analyst.

The real paradox, as mentioned by Green, does not refer to the "unconscious" feeling of culpability, but rather to the narcissist feeling of culpability, more exactly the unconscious feeling of culpable narcissism. Green admits that the relation with the object serves as a disguise for a narcissist relation, with the final aim to question the object-centred relation as such (A. Green, 1993, p. 141).

There is something special in the way in which the patient shows his opposition regarding the image of the oedipal father, setting aside for a long period of time the partial reading of his father's letters from past when he was in the army, in finding difficulties in asking his mother to tell him about his father, in meeting his father's sister for the same reason, in trying to identify himself with his father through his role of a father. It is impossible for him to imagine his father as his mother's partner, and his parents being a happy couple.

Chasseguet-Smirgel (1990, p. 100) writes about the gap in the Ego caused by the defect of introjection and assimilation with the father, "... which is an unconscious process and which implies a relation based on love, admiration and sensitive proximity, and which cannot be filled in by imitating the father and parental attributes, divested in a narcissist way, but only through an attempt to clear oneself completely from the parentage links" (J. Chasseguet-Smirgel, 1990, p. 100). In in patient's story the father's image provided by the mother seems to be void, lifeless and lacking conscience.

The problem deriving from the oedipal non-integration is obvious, as well as the one related to the difficulty in recalling the father's representation. The resistance on developing this representation is gradually given up, but with great difficulty. D. Suchet (2017) states that the meeting with the sexual stranger happens in the analysis. During the cure, the oedipal development allows the stranger to be felt in the meeting's associativity. In cases when the 
patient is at the limit of neurosis, the entry of the sexual attribute is a real exclamation by an alien body, threatening the mental life, even in the context of the analysis (D. Suchet, 2017, p. 165).

Green underlines that the de-objectalising function is the most radical opposition procedure for working with the mourning (A. Green, 1993). The central moment refers to the objectalising function and it is linked with the fact that it should consider an inevitable contradiction and namely the fact that the role of the primary object is decisive and that one more object is always present. And you cannot attribute a secondary role to this second object - father in Oedipus complex. We cannot consider this object as a projected reflection of the primary object (A. Green, 1993, p. 119).

Green quotes Freud, who insists on the fact that primitive love looks a lot like hate, called "ruthless love" by Winnicott. The confusion of these two conditions makes us think that when a subject-object separation intervenes, a return to the narcissist organisation may happen, in which these two conditions are immediately confused again; in other moments, the hate towards the independence of the object, which indicates its separation, is still infiltrated by regrets related to the time when the object is consistent with subject's omnipotence (A. Green, 1993, p. 150). In patient's case, it seems that he abandons with great difficulty his position of omnipotence in relation to his mother and his father.

In the structure level, the patient gets close to a "narcissistic organization" as described by A. Green, who distinguishes three versions of this organization. One of them is manifested as a closing period in which the narcissistic organization works against the realisation of unification and rather extends the process towards maintaining an unchanged union, the masochism and the failure of the cure being the guards of a de-objectalising function where transference is subject to a work similar to that of Penelope between the meetings (A. Green, 1993, p. 150). It is important to mention that after the more successful meetings; the patient comes back with a speech where he produces the impression that nothing what was previously mentioned was integrated by him.

In Constructions in Analysis Freud (1937) talks about the patient who agrees with the therapist only when he finds out the entire truth, and this moment is often far away. The interpretation of patient's construction rejection comes from the incompleteness, from the fact that the construction did not say everything (S. Freud, 1937, p. 331). Probably, the gradual lifting of the repression, on one hand, and the attempt to update/construct more things related 
to the pre-oedipal period, on the other hand, can be accepted by the patient only in the complete version.

N. Zilkha (2013, p. 669) talks about the continuous effort to become the subject own thoughts, feelings, and history. M. Parsons (2016) underlines that this activity of "subjectivation" (concept introduced by R. Cahn, 1991) implies taking one's own life in possession, as well as assuming responsibility towards the person one is. He states that we are getting close to the form of internal authority present within us (M. Parsons, 2016, p. 27). The responsibility, which is absent in patient's relations with the daughter, wife, and with himself, but excessively present in his relation with his mother, looks like a form of irresponsibility, by maintaining mother's illusion regarding her special relation with her son.

\section{Conclusions}

Carrying out the analysis of this case, we fully support the hypotheses formulated by C. Chabert (2015, p.124-129), who states that some conditions are necessary to work through to become organised in the system. Rememorizing and repeating in the work of making connection between memories and phantasms to be possible; the most important being the representative process, which is the main path for acquiring the psychical language which combines meaning and significance, assimilating verbal signs with pleasure/displeasure conditions... C. Chabert refers to Freud's Studies in Hysteria (1895), where he talks about the separation of false connections so as to retrieve the genuine and "historically" reasoned ones. Being one of the important problems in the relation with the patient, working through is impeded by the patient's need to frequently reject certain representations. According to C. Chabert, the ideal aim of working through is focused on the disappearance of the compulsive tendency to repeat the same thing and to be available for something else, leading to the pleasure of accepting the limits, because the past gets transformed into memory and repetition in meaning. Hence, this procedure of working through in clinical cases with early morning needs time and effort so as to ensure a case impregnated with meaning and divided and individuated characters. 


\section{REFERENCES}

BOKANOWSKI, T. (2019). La bisexualité dans la cure [Bisexuality in the cure]. Bulletin of the SPP, $79^{\text {th }}$ Congress of French Language Psychoanalysts, May $30^{\text {th }}-J u n e 2^{\text {nd }} 2019$, pp. 5561.

CHABERT, C. (1999). Les voies intérieures [The inner paths]. Rev Fr Psychanal [French Journal of Psychoanalysis] LXIII(5): 1445-1488.

CHABERT, C. (2015). L'excès et la pénurie: affect dans la cure [Excess and shortage: affect in the cure]. Bulletin of the FEP, $28^{\text {th }}$ Conference of the FEP, ,, Trop-pas assez” [Too much-not enough], Stockholm, March 26 $6^{\text {th }}-29^{\text {th }} 2015$, pp. 123-133.

CHASSEGUET-SMIRGEL, J. (1990). L'Idéal du Moi et la sublimation dans le processus créateur. [The Ideal of the Ego and sublimation in the creative process]. Maladie d'idéalité. Essai psychanalytique sur l'idéal du moi. [Illness of ideality. Psychoanalytic essay on the ideal of the ego] Editions Universitaires, p. 205.

FREUD, S. (1914). Remembering, Repeating and Working-Through. Further Recommendations on the Technique of Psycho-Analysis. Psycho-Analysis Technique. Works, vol. XI. Three, Bucharest, 2004, pp.137-147.

FREUD, S. (1924). Economic problem of masochism. Psychology of the Unconsciousness. Works, vol. III. Three, Bucharest, 2004, pp. 263-274.

FREUD, S. (1937). Constructions in Analysis. Psycho-Analysis Technique. Works, vol. XI. Three, Bucharest, 2004, pp. 323-336.

GREEN, A. (1993). Le travail du négatif [The work of the negative]. Éd. de Minuit, Paris, 1993, p. 400.

PARSONS, M. (2016) Auteurs de notre propre Autorité [Authors of our own Authority]. Bulletin of the FEP, $29^{\text {th }}$ Conference of the FEP, ,Authority”, Berlin, March $17^{\text {th }}-20^{\text {th }} 2016$, pp. 21-31.

SECHAUD, E. (2005). Perdre, sublimer [Loss, sublimation]. Bulletin of the SPP, $65^{\text {th }}$ Congress of French Language Psychoanalysts, May $5^{\text {th }}-8^{\text {th }} 2005$, pp. 21-84.

SUCHET, D. (2017). Le sexuel infantile, une présence étrangère interne chez l'adulte [Infantile sexuality, an internal foreign presence in the adult]. The FEP Bulletin, $30^{\text {th }}$ Conference of the FEP, „Le propre et l'etranger”, Le Haye, April $6^{\text {th }}$-9th 2017, pp. 163-169.

ZILKHA, N. (2013). Au fil de transfert, jouer [Throughout transfer, playing] Rev Fr Psychanal [French Journal of Psychoanalysis]. 77(3): 659-670. 